\title{
The role of Namibia Field Epidemiology and Laboratory Training Programme in strengthening the public health workforce in Namibia, 2012-2019
}

\author{
Kofi Mensah Nyarko (D) , ${ }^{1,2}$ Leigh Ann Miller, ${ }^{3}$ Andrew L Baughman, ${ }^{3}$ \\ Puumue Katjiuanjo, ${ }^{1}$ Michele Evering-Watley, ${ }^{3}$ Simon Antara, ${ }^{1}$ Penehafo Angula, ${ }^{2}$ \\ Honore K Mitonga, ${ }^{2}$ Dimitri Prybylski, ${ }^{3}$ Eric J Dziuban, ${ }^{3}$ Emmy-Else Ndevaetela ${ }^{1}$
}

\begin{abstract}
To cite: Nyarko KM, Miller LA, Baughman AL, et al. The role of Namibia Field Epidemiology and Laboratory Training Programme in strengthening the public health workforce in Namibia, 2012-2019. BMJ Global Health 2021;6:e005597. doi:10.1136/ bmjgh-2021-005597
\end{abstract}

Handling editor Seye Abimbola

Received 4 March 2021

Accepted 28 March 2021

Check for updates

C Author(s) (or their employer(s)) 2021. Re-use permitted under CC BY-NC. No commercial re-use. See rights and permissions. Published by BMJ.

${ }^{1}$ Namibia Ministry of Health and Social Services, Windhoek, Khomas, Namibia

${ }^{2}$ School of Public Health,

University of Namibia, Windhoek Namibia

${ }^{3}$ US Centers for Disease Control and Prevention, Windhoek, Namibia

Correspondence to Dr Kofi Mensah Nyarko; konyark022@yahoo.com

\section{ABSTRACT}

Namibia faces a critical shortage of skilled public health workers to perform emergency response operations, preparedness activities and real-time surveillance. The Namibia Field Epidemiology and Laboratory Training Programme (NamFELTP) increases the number of skilled public health professionals and strengthens the public health system in Namibia. We describe the NamFELTP during its first 7 years, assess its impact on the public health workforce and provide recommendations to further strengthen the workforce. We reviewed disease outbreak investigations and response reports, field projects and epidemiological investigations conducted during 2012-2019. The data were analysed using descriptive methods such as frequencies and rates. Maps representing the geographical distribution of NamFELTP workforce were produced using QGIS software V.3.2. There were no formally trained field epidemiologists working in Namibia before the NamFELTP. In its 7 years of operation, the programme graduated 189 field epidemiologists, of which 28 have completed the Advanced FELTP. The graduates increased epidemiological capacity for surveillance and response in Namibia at the national and provincial levels, and enhanced epidemiologist-led outbreak responses on 35 occasions, including responses to outbreaks of human and zoonotic diseases. Trainees analysed data from 51 surveillance systems and completed 31 epidemiological studies. The NamFELTP improved outcomes in the Namibia's public health systems; including functional and robust public health surveillance systems that timely and effectively respond to public health emergencies. However, the current epidemiological capacity is insufficient and there is a need to continue training and mentorship to fill key leadership and strategic roles in the public health system.

\section{INTRODUCTION}

Namibia is a large, sparsely populated subSaharan African country with 13 regions and a population of 2.5 million. ${ }^{1}$ Namibia lacks an adequate healthcare workforce, and the health system is mostly clinically focused

\section{Summary box}

- Namibia Field Epidemiology and Laboratory Training Programme (NamFELTP) has built field epidemiology capacity in surveillance and outbreak response at the national, regional and district levels using both front-line and advanced level FELTP.

- NamFELTP improved critical outcomes in the public health system, including enhancing public health surveillance systems to effectively and rapidly respond to public health emergencies. Before the programme began, there was a weak surveillance system, no surveillance system evaluation and data analyses were conducted, and there was poor response capacity.

- Trainees come from relevant Ministries and agencies, including Health and Social Services (MoHSS); Agriculture, Water and Forestry (MAWF); and Defence as well as Namibia Institute of Pathology to facilitate a multidisciplinary and a one-health approach towards public health preparedness and response.

- Advanced and front-line graduates hold positions of authority within national and regional health authorities of the MoHSS and veterinary services department of the MAWF.

with very few public health experts. The critical shortage of skilled public health workers includes epidemiologists, biostatisticians and other quantitative scientists with skills in data collection and analysis. ${ }^{2}$

A primary goal of field epidemiology is to guide, as quickly as possible, the processes of selecting and implementing effective and appropriate interventions to lessen or prevent illness or death when such problems arise. ${ }^{3}$ To address the deficit of trained public health staff, in 2012, the Namibia Ministry of Health and Social Services (MOHSS), in partnership with the US Centers for Disease Control and Prevention (US-CDC), established the 
Namibia Field Epidemiology and Laboratory Training Programme (NamFELTP). The programme is modelled after the US-CDC Epidemic Intelligence Service (EIS) which has trained public health workers in over 70 countries to respond to outbreaks of infectious diseases to minimise impact and prevent national or international spread. ${ }^{45}$ In Namibia, trainees address high prevalence infectious diseases (eg, HIV and tuberculosis), zoonotic diseases (eg, anthrax) and non-communicable diseases (NCDs) such as cardiovascular disease, cancer, diabetes and hypertension. ${ }^{6-8}$ Namibia requires an epidemiologically trained public health workforce to help with emergency response operations, preparedness and real-time surveillance and reporting, as well as to manage the public health laboratory system.

Globally, the Field Epidemiology Training Programme (FETP) is structured into three tiers (figure 1). Each tier addresses a need to improve surveillance, epidemiology, response and scientific communication skills of public health workers. The front-line tier is a 3-month training that focuses on strengthening the surveillance system at the district level along with improving the participants' skills within the context of their current job responsibilities. The intermediate tier is a 9-month training that trains mid-level epidemiologists and focuses on strengthening the surveillance system at the regional or provincial level. The advanced tier is a 2-year training that prepares trainees for leadership positions within the public health system. The NamFELTP was introduced to enhance epidemiology skills at various levels, that is at the district, regional and national to strengthen the public health system of Namibia.

At the inception of the programme, the MoHSS had no field epidemiologists or any staff with a related discipline. There was no domestic training programme in field epidemiology. Field epidemiology functions were performed on an ad hoc basis by clinicians (doctors and nurses) who had no or limited training. We describe NamFELTP in its first 7 years, assess its impact on the public health workforce, and provide recommendations for improving the programme and public health system.

\section{NAMFETP PROGRAMME DESCRIPTION}

The NamFELTP is hosted by the MoHSS and implements the programme with the University of Namibia (UNAM) School of Public Health. Trainees of the 2-year advanced programme matriculate in an MSc Applied Field
Epidemiology degree programme in UNAM, while those that graduate from the 3-month front-line programme receive a certificate of participation. Trainees come from MoHSS, Agriculture, Water and Forestry (MAWF); and Defence, and Namibia Institute of Pathology to ensure a multidisciplinary and a one-health approach towards public health preparedness and response. The onehealth concept is a collaborative, multisectoral and transdisciplinary approach with the goal of achieving optimal health outcomes by recognising the interconnection between human health, animal health and their shared environment. ${ }^{9}$ Using a one-health framework where humans, animals and the environment are viewed as interconnected, the NamFELTP recruited people across these related fields and trained them to jointly respond to public health emergencies. The selection process for the front-line tier is done though nominations of qualified participants from their various ministries and agencies. The UNAM admission process selects candidates for the advanced programme. A Resident Advisor with expertise in field epidemiology led the advanced programme during 2014-2019, with support from CDC, UNAM faculty and external consultants.

NamFELTP modified the standard US-CDC EIS training materials to incorporate the local context for the trainees. The curriculum consists of $25 \%$ didactic classroom sessions and $75 \%$ field placement as in other FELTPs. ${ }^{10}{ }^{11}$ Didactic training modules cover principles of field epidemiology, data management, biostatistics, public health surveillance, epidemiology of priority public health conditions and NCDs, leadership and management, advanced epidemiological methods, preventive effectiveness (health economics), scientific communication, mentorship and research methods. The field placement outputs are outbreak investigation and response, data quality audits, secondary data analysis of surveillance data, surveillance system evaluation and epidemiological studies. The trainees conduct these field placement activities in their assigned districts and regions by collecting the relevant data, analysing and producing field output reports under the supervision of their mentors with the guidance of the resident advisor. The mentor to resident mentee ratio in the advance programme is one mentor to three mentees while that of the front line is a one mentor to five or six mentees. Trainees are expected to present or disseminate their findings at international scientific conferences as part of their graduation requirements.

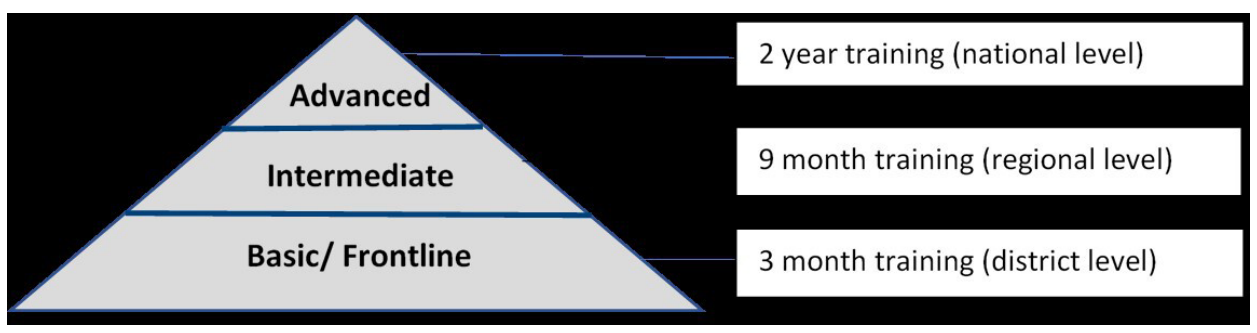

Figure 1 Field Epidemiology Training Programme pyramid. ${ }^{32}$ 


\section{APPROACH}

This is a description of NamFELTP from its inception in January 2012 through January 2019. NamFELTP implemented two of the three FELTP tiers; front line started in 2012 and was previously called the short course, and Advanced FELTP started in 2014 (figure 1). All cohorts enrolled within the 7 years' period were reviewed. We conducted records review and described the programme implementation and evaluated the programme deliverables.

\section{EVALUATION OF PROGRAMME DELIVERABLES}

Disease outbreak investigations and response reports were reviewed to determine the number and types of outbreaks investigated. We reviewed surveillance data analysis reports and surveillance system evaluation reports to determine any changes in key surveillance indicators such as data quality and timeliness of reporting. Epidemiological investigations and other field projects conducted were also reviewed to determine their impact on the health system. We assessed the trainee's presentation of their field project outputs made at international scientific conferences and also the current positions of the graduates as a result of the training acquired.

Data were analysed and summarised into frequencies, proportions and rates, and presented in tables. A map representing the geographical distribution of the NamFELTP workforce was produced using QGIS software V.3.2. Per the International Health Regulation (IHR) standard of having one trained epidemiologist per 200000 population, ${ }^{12}$ we calculated the number of Advanced level trainees trained per 200000 population by region using the 2018 regional population estimates. ${ }^{14}$

\section{ENROLMENT OF TRAINEES INTO THE FRONT-LINE FELTP}

In total, NamFELTP trained 161 front-line health workers from all 13 regions and all 34 districts of Namibia with no drop-outs (figure 2). Health professionals trained in the Front-line Programme were primarily female $(63 \%)$ and included medical, veterinary, laboratory and environmental health practitioners (table 1). A majority were healthcare workers $(71 \%)$ and environmental health practitioners $(24 \%)$ with few animal health workers $(5 \%)$. The capitol region of Khomas has the highest number (20). In Namibia, the Front-line Programme trained 5-20 staff per region.

\section{ENROLMENT OF TRAINEES INTO THE ADVANCED FELTP}

A total of 40 trainees from 9 regions have enrolled in the Advanced FELTP (figure 2). The WHO-IHR standard for number of trained epidemiologists is one field epidemiologist per 200000 population. For Namibia nationally, that will require 13 trained epidemiologists. Namibia's Advanced FELTP programme enrolled six cohorts during 2014-2019 (range: 5-9 trainees per cohort) and graduated 28. The last two cohorts have 11 trainees in training.

The majority of NamFELTP trainees were females. NamFELTP trainees were healthcare workers, primarily nurses, as well as three medical doctors (enrolled in the 2017 and 2019 cohorts), followed by environmental health practitioners, animal health workers and a demographer (table 1). The highest proportion, $45 \%(18 / 40)$ were from the Khomas region, which is the capital region, location of the UNAM and national government ministries, including MoHSS and MAWF headquarters. This is logical; most of the public health workforce in the country is in the Khomas region. Other regions have enrolled trainees in an ad hoc

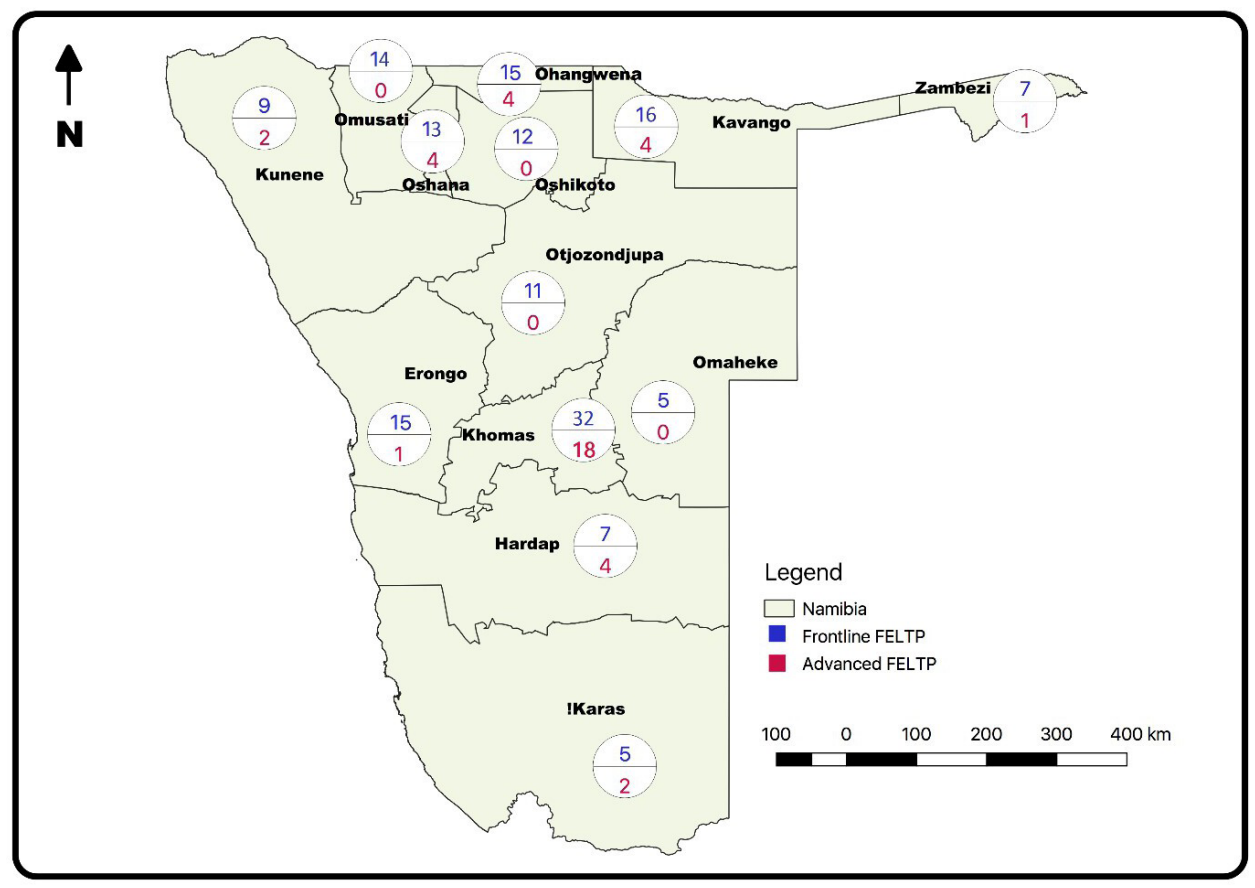

Figure 2 Number and location of advanced and frontl-ine FELTP graduates by region, Namibia, 2020. ${ }^{33}$ FELTP, Field Epidemiology and Laboratory Training Programmes. 
Table 1 Characteristics of front-line and advanced FELTP trainees in Namibia, 2012-2019

\begin{tabular}{|c|c|c|c|c|c|}
\hline Characteristics & Population & $\begin{array}{l}\text { No enrolled } \\
(\%)\end{array}$ & $\begin{array}{l}\text { No enrolled } \\
\text { per } 200000 \\
\text { population }\end{array}$ & $\begin{array}{l}\text { No completed } \\
(\%)\end{array}$ & $\begin{array}{l}\text { No } \\
\text { completed } \\
\text { per } 200000 \\
\text { population }\end{array}$ \\
\hline \multicolumn{6}{|l|}{ Front-lineFELTP } \\
\hline \multicolumn{6}{|l|}{ Sex } \\
\hline Male & - & $59(37)$ & & $59(37)$ & \\
\hline Female & - & $102(63)$ & & $102(63)$ & \\
\hline \multicolumn{6}{|l|}{ Professional category } \\
\hline $\begin{array}{l}\text { Healthcare workers (medical doctors, nurses } \\
\text { and medical technologist) }\end{array}$ & - & $114(71)$ & & $114(71)$ & \\
\hline Environmental health practitioners & - & $38(24)$ & & $38(24)$ & \\
\hline $\begin{array}{l}\text { Animal health workers (veterinarians and } \\
\text { veterinary technicians) }\end{array}$ & - & $8(5)$ & & $8(5)$ & \\
\hline Other (statistician) & - & $1(0.6)$ & & $1(0.6)$ & \\
\hline \multicolumn{6}{|l|}{ Region } \\
\hline Khomas & 447600 & $20(12)$ & 8.9 & $20(12)$ & 8.9 \\
\hline Hardap & 90300 & $7(4)$ & 15.5 & $7(4)$ & 15.5 \\
\hline Karas & 89200 & $5(3)$ & 11.2 & $5(3)$ & 11.2 \\
\hline Kavango & 243900 & $16(10)$ & 13.1 & $16(10)$ & 13.1 \\
\hline Kunene & 102500 & $9(6)$ & 17.6 & $9(6)$ & 17.6 \\
\hline Ohangwena & 260200 & $15(9)$ & 11.5 & $15(9)$ & 11.5 \\
\hline Erongo & 195700 & $15(9)$ & 15.3 & $15(9)$ & 15.3 \\
\hline Omaheke & 75700 & $5(3)$ & 13.2 & $5(3)$ & 13.2 \\
\hline Omusati & 252700 & $14(9)$ & 11.1 & $14(9)$ & 11.1 \\
\hline Oshana & 194600 & $13(8)$ & 13.4 & $13(8)$ & 13.4 \\
\hline Oshikoto & 200700 & $12(7)$ & 12.0 & $12(7)$ & 12.0 \\
\hline Otjozondjupa & 158200 & $11(7)$ & 13.9 & $11(7)$ & 13.9 \\
\hline Zambezi & 102300 & $7(4)$ & 13.7 & $7(4)$ & 13.7 \\
\hline National level & 2413600 & $12(7)$ & - & $12(7)$ & - \\
\hline Total & & 161 & & 161 & \\
\hline \multicolumn{6}{|l|}{ Advanced feltp } \\
\hline \multicolumn{6}{|l|}{ Sex } \\
\hline Female & - & $29(72)$ & & $22(79)$ & \\
\hline Male & - & $11(28)$ & & $6(21)$ & \\
\hline \multicolumn{6}{|l|}{ Professional categories } \\
\hline $\begin{array}{l}\text { Healthcare workers (medical doctors, nurses and } \\
\text { medical technologist) }\end{array}$ & - & $25(62)$ & & $19(68)$ & \\
\hline Environmental health practitioners & - & $8(20)$ & & $4(14)$ & \\
\hline $\begin{array}{l}\text { Animal health workers (veterinarians and } \\
\text { veterinary technicians) }\end{array}$ & - & $6(15)$ & & $5(18)$ & \\
\hline Others (demographer) & - & $1(3)$ & & & \\
\hline \multicolumn{6}{|l|}{ Region } \\
\hline Khomas & 447600 & $18(45)$ & 8 & $10(36)$ & 4.5 \\
\hline Hardap & 90300 & $4(10)$ & 8.9 & $4(14)$ & 8.9 \\
\hline Karas & 89200 & $2(5)$ & 4.5 & $2(7)$ & 4.5 \\
\hline Kavango & 243900 & $4(10)$ & 3.3 & $2(7)$ & 1.6 \\
\hline Kunene & 102500 & $2(5)$ & 3.9 & $2(7)$ & 3.9 \\
\hline
\end{tabular}




\begin{tabular}{|c|c|c|c|c|c|}
\hline Characteristics & Population & $\begin{array}{l}\text { No enrolled } \\
(\%)\end{array}$ & $\begin{array}{l}\text { No enrolled } \\
\text { per } 200000 \\
\text { population }\end{array}$ & $\begin{array}{l}\text { No completed } \\
(\%)\end{array}$ & $\begin{array}{l}\text { No } \\
\text { completed } \\
\text { per } 200000 \\
\text { population }\end{array}$ \\
\hline Ohangwena & 260200 & $4(10)$ & 3.1 & $3(1)$ & 2.3 \\
\hline Erongo & 195700 & $1(3)$ & 1 & $1(4)$ & 1 \\
\hline Omaheke & 75700 & $0(0)$ & 0 & $0(0)$ & 0 \\
\hline Omusati & 252700 & $0(0)$ & 0 & $0(0)$ & 0 \\
\hline Oshana & 194600 & $4(10)$ & 4.1 & $4(14)$ & 4.1 \\
\hline Oshikoto & 200700 & $0(0)$ & 0 & $0(0)$ & 0 \\
\hline Otjozondjupa & 158200 & $0(0)$ & 0 & $0(0)$ & 0 \\
\hline Zambezi & 102300 & $1(3)$ & 2 & $0(0)$ & 0 \\
\hline Total & 2413600 & 40 & & 28 & \\
\hline
\end{tabular}

FELTP, Field Epidemiology and Laboratory Training Programmes.

fashion based on the interest of trainee and willingness of regional leadership to release staff for training.

\section{REGIONAL DISTRIBUTION OF FELTP TRAINEES}

Both the front-line and advanced FELTP trainees are centralised within the Khomas region which is the national capital. All regions have front-line trainees; however, for the advanced programme, four regions (Omaheke, Omusati, Oshikoto and Otjozondjupa) have not enrolled any trainees (figure 2).

\section{DISEASE OUTBREAK INVESTIGATION AND RESPONSE}

NamFELTP advanced trainees investigated 35 disease outbreaks in 5 years. Outbreaks dealt with cholera, measles, rubella, neonatal tetanus, malaria, schistosomiasis ${ }^{15}$ and hepatitis $\mathrm{E}$, and zoonotic diseases such as rabies in domestic dogs, foot and mouth disease in cattle, anthrax among wildlife and domestic animals (cattle and goats), and Crimean-Congo haemorrhagic fever (CCHF) in humans (table 2). CCHF, a zoonotic viral disease caused by tick bites, is endemic in Namibia. This is an important disease because it affects numerous agricultural workers. Three outbreaks were reported during 2017-2018 with four cases among agricultural workers, including two fatalities. NamFELTP alumni and trainees participated in all three CCHF outbreak investigations and provided health education, identified and traced contacts of infected persons, conducted environmental assessments and administered acaricide to animals to kill ticks in agricultural areas.

In October 2017, the Ministry of Environment and Tourism reported a suspected anthrax outbreak in the Kavango region where hippopotamus and buffalo carcasses were characteristic of anthrax. During OctoberDecember 2017, 155 hippopotamuses, 86 buffalos and 2 impalas died. The response was conducted using a onehealth approach recognising common threats to animal and human health. ${ }^{16}$ NamFELTP trainees determined how many humans were exposed to anthrax, administered postexposure prophylaxis (PEP) and delivered health education to community members and healthcare workers. NamFELTP trainees and alumni identified 142 exposed persons who handled or ate hippopotamus meat and provided PEP. No subsequent human cases of anthrax during this outbreak in wildlife, suggesting success of the timely and effective public health intervention. NamFELTP trainees also confirmed multiple suspected measles outbreaks as rubella which lead to the introduction of the rubella vaccination on the country.

\section{SURVEILLANCE DATA ANALYSIS AND SURVEILLANCE SYSTEM EVALUATION AND OTHER FIELD PROJECTS}

Trainees conducted 51 surveillance data analyses and surveillance system evaluations and 31 epidemiological studies on priority public health conditions and other disease programmes (table 2). The surveillance data analysis and surveillance system evaluations showed enhanced data quality and improved timeliness in reporting of surveillance data over the period. The planned epidemiological studies have resulted in policy changes such as the rabies serosurvey among vaccinated domestic dogs showed lower immunogenicity among dogs who were vaccinated only once a year and this resulted in a twice yearly antirabies vaccination. Trainees of Advanced FELTP have lead or coauthored three peer-review manuscripts. ${ }^{15-17}$ NamFELTP graduates currently hold key positions in MoHSS and MAWF. These include Epidemiology Division head at MoHSS and Chief Veterinary Epidemiologist at MAWF.

\section{ATTENDANCE AT INTERNATIONAL SCIENTIFIC CONFERENCES}

Training Programmes in Epidemiology and Public Health Interventions Network (TEPHINET) is a global network of FETPs, while African Field Epidemiology Network (AFENET) is a networking alliance of African Field Epidemiology and Laboratory Training Programmes (FELTPs). The major scientific conferences for FELTP programmes are TEPHINET Global Scientific Conference and AFENET 
Table 2 Outbreak investigations, surveillance data analyses and evaluations conducted in Namibia by advanced NamFELTP trainees, 2014-2019

\begin{tabular}{|c|c|c|}
\hline Characteristic & No & Percentage \\
\hline \multicolumn{3}{|l|}{ Outbreak investigations and response } \\
\hline Zoonotic diseases (foot and mouth, rabies, anthrax, CCHF, Rift Valley fever) & 13 & 37 \\
\hline Vaccine preventable diseases (measles, rubella, chickenpox, tetanus, meningitis) & 10 & 29 \\
\hline Food-waterborne diseases (cholera, schistosomiasis, acute watery diarrhoea, hepatitis E virus) & 8 & 23 \\
\hline Malaria & 3 & 9 \\
\hline H1N1 influenza & 1 & 3 \\
\hline Subtotal & 35 & 100 \\
\hline \multicolumn{3}{|l|}{ Surveillance data analyses and surveillance system evaluation } \\
\hline TB/HIV & 17 & 33 \\
\hline Vaccine preventable disease (measles, rubella, chicken pox, tetanus, meningitis) & 11 & 22 \\
\hline Zoonotic diseases (foot and mouth, rabies, brucellosis, bovine spongiform encephalitis) & 7 & 14 \\
\hline Food-waterborne diseases (cholera, schistosomiasis, acute watery diarrhoea) & 5 & 10 \\
\hline Malaria & 5 & 10 \\
\hline Maternal and Neonatal Health & 3 & 6 \\
\hline Others (accident and injuries, mental health, clubfoot) & 3 & 6 \\
\hline Subtotal & 51 & 100 \\
\hline \multicolumn{3}{|l|}{ Epidemiological studies } \\
\hline Non-communicable diseases (hypertension, diabetes, breast, cervical and prostate cancers) & 8 & 26 \\
\hline Zoonotic diseases (rabies, porcine cysticercosis, foot and mouth) & 6 & 19 \\
\hline Others (food safety, patient referral patterns, hepatitis E virus) & 4 & 13 \\
\hline $\begin{array}{l}\text { Maternal and child health (adverse pregnancy outcomes, neonatal mortality, stillbirth and } \\
\text { childhood undermalnutrition) }\end{array}$ & 4 & 13 \\
\hline TB & 4 & 13 \\
\hline Vaccine preventable diseases (measles, hepatitis B) & 2 & 7 \\
\hline HIV & 2 & 7 \\
\hline Malaria & 1 & 3 \\
\hline Subtotal & 31 & 100 \\
\hline Total & 117 & \\
\hline
\end{tabular}

NamFELTP, Namibia Field Epidemiology and Laboratory Training Programme; TB, tuberculosis.

Regional Scientific Conference. FELTP trainees present their scientific work at these international conferences as part of field placement competencies to demonstrate their ability to present at international fora.

Since 2012, NamFELTP trainees have attended and presented at six International Conferences, including two TEPHINET and three AFENET conferences. NamFELTP's 35 trainees presented 59 abstracts, including 17 (29\%) oral and $42(71 \%)$ posters, with three award winning poster presentations in 2016, 2017 and 2018.

\section{PROGRAMME IMPACT}

Local capacity is crucial for effective and timely public health responses. District health officers are often the first people called during a public health emergency and are prioritised for front-line FETP training. ${ }^{18}$ NamFELTP training resulted in producing a significant increase in skilled workforce, 161 front-line field epidemiologists and 28 Advanced field epidemiologists, as compared with zero at the inception of the training programme. This achievement has resulted in timely detection of outbreaks. The improved epidemiological capacity at district and regional levels enhances data quality and timeliness of reporting. Detecting and responding to disease outbreaks at lower levels in a timely manner helps prevent spread of outbreak. After the Ebola outbreak in 2014, West African countries including Liberia, Côte d'Ivoire, Senegal, and Togo implemented front-line FELTP to increase and improve their epidemiological capacity at the lower levels to enhance data quality and timeliness of reporting. ${ }^{18} 19$ Strengthening the public health workforce in low-income and middle- income countries is crucial in ensuring that countries have the needed capacity to prepare and respond to public health emergencies. 
Advanced NamFELTP trained medical, veterinary, laboratory and environmental health practitioners in a comprehensive approach to surveillance and outbreak response within the one-health approach. This onehealth approach embedded in the NamFELTP yielded a remarkable response to major zoonotic disease outbreaks such as recurring CCHF outbreaks and the Anthrax outbreak among hippopotamus in Bwabwata National Park, Namibia. ${ }^{16}$ However, only three physicians $(7.5 \%)$ have been enrolled, in contrast to other FELTP programmes where many trainees are physicians. A possible reason for low physician enrolment is the need for physicians to deliver clinical services since training for medical doctors within Namibia began in 2010; prior to that date all physicians trained outside the country. ${ }^{20}{ }^{21}$ Enrolling more physician into the programme is crucial to ensure the programme viability.

According to the Global FETP Roadmap, evidence justifying the target of 1 trained field epidemiologist/200 000 population is thin and serves as a general guide to the sufficient number of field epidemiologists in a country. A few countries use different metrics such as one field epidemiologist per district or per national programme and can accommodate their demographics, health system and geopolitical structures, and population needs (eg, percent rural vs urban population).$^{22}$ In the case of Namibia with a population of 2.5 million, although 28 Advanced FETP trainees have matriculated, this number and geographic placement of epidemiologists is insufficient to fill key leadership and strategic roles in the country's public health system for several reasons including inadequate number of epidemiologist for the huge land mass, the need of several epidemiologist to manage the varied disease programmes at the national level and limited expertise for the control of emerging and re-emerging disease considering the countries disease profile. Expanding the programme to include provincial/regional staff and other relevant agencies by giving quota to these regions and sectors will be critical to ensure a well-distributed workforce to respond adequately to public health emergencies.

NamFELTP remains the country's premier public health training programme and graduates must support public health efforts beyond field epidemiology. In many cases, NamFELTP graduates return to clinical healthcare after their training rather than contributing to the public health sector because there is currently no position as epidemiologists in the Human Resource staff establishment of the Public Service Commission for Ministry of Health, hence no public health career path for the graduates. Because of these limitations, there are no full-time employees in MoHSS positions classified as epidemiologists. This situation is similar to other African countries as indicated in the third Ministerial Round Table at the seventh AFENET Scientific Conference in Maputo, Mozambique in 2018, where only three countries (Liberia, Tanzania and Zimbabwe) out of 12 African countries evaluated had a formal policy on career path for field epidemiology graduates. ${ }^{23}$ Four regions in Namibia have no trained field epidemiologists. Some graduates left government service to work with private and non-governmental organisations. The critical shortage of available public health workers, especially those with specialised training in field epidemiology, diminishes preparedness and response throughout the country. Moreover, Namibia covers a vast landmass with a dispersed, low-density population. There is a need for field epidemiologists to work in remote geographical areas to detect disease outbreaks at their origin rather than relying on a disproportionate number of Advanced graduates located in the Khomas region.

Surveillance systems and responses to public health events have improved because of NamFELTP. Trainees and alumni have responded in a timely manner to 35 outbreak investigations. Prompt public health response by the FELTP during the 2017 anthrax outbreak among wildlife in Bwabwata National Park, ${ }^{24}$ led to zero human cases compared with similar outbreaks among hippopotamuses in Zambia ${ }^{2526}$ and Zimbabwe $^{27}$ which had multiple human cases and deaths. The inclusion of rubella vaccination as part of nationwide childhood routine immunisations in $2017^{28}$ was a result of the multiple confirmed rubella outbreaks investigated.

NamFELTP trainees conduct secondary surveillance data analyses periodically to determine disease trends and to evaluate control and prevention measures to support planning and decision making. Surveillance system evaluations identify gaps in the surveillance system and provide recommendations to strengthen the surveillance system. As in other FELTP programmes, such epidemiological analyses and evaluations help improve surveillance system for both human and animal health. ${ }^{29} 30$ A rabies seroprevalence survey conducted among dogs in the Ohangwena region identified lower immunogenicity of rabies in dogs who were vaccinated once a year compared with twice a year. ${ }^{31}$ These data led to increasing national rabies vaccination campaigns to twice a year.

\section{CONCLUSION}

In summary, NamFELTP trained 161 front-line and 28 advanced graduates who are contributing to the human and animal health systems. NamFELTP has greatly improved critical outcomes in the public health system, including enhancing public health surveillance systems to respond effectively and rapidly to public health emergencies from previously where there was a weak surveillance system, no surveillance system evaluation and data analysis conducted, and no capacity to respond to public 
health emergencies in an effective and timely manner. CDC, WHO, AFENET and TEPHINET have contributed funds and technical assistance for NamFELTP. Government of the Republic of Namibia (GRN) ownership is key for the success and sustainability of the programme.

Despite the crucial role and functions that field epidemiologists and other public health workers play, there are no posts for epidemiologists within the GRN system. Consequently, it is necessary for the Public Service Commission to adapt job descriptions and requirements to establish epidemiologist positions. These steps can provide Namibia with the skilled epidemiological workforce it requires for sustained health security. The training and mentorship in NamFELTP should continue to fill key leadership and strategic roles in the public health system. We recommend that the MoHSS and MAWF purposefully recruit trainees from the four regions with no trainees for the advanced programme to ensure equitable distribution of public health workforce for effective and timely response to public health threats.

Acknowledgements We thank the NamFELTP trainees and alumni, who are on the front lines of fighting diseases in Namibia. We are indebted to CDC staff David Lowrance for all his efforts to establish NamFELTP, Roopal Patel for early program management guidance, and Simon Agolory, who provided strong advocacy and support for NamFELTP. We also thank the former Ministers of Health and Social Services, Dr Richard Kamwi and Dr Bernard Haufiku for their support to the program. Finally, we thank Dr Kalumbi Shangula, the current Minister of Health and Social Services, for his unflinching support.

Contributors KMN and LAM conceptualised and designed the manuscript, and provided overall management oversight for manuscript preparation, wrote portions and critically reviewed manuscript. ALB, PK, ME-W, SA, PA, HKM, DP, EJD and E-EN wrote portions of manuscript and critically reviewed the manuscript. All authors reviewed and approved the final version of the manuscript.

Funding The authors have not declared a specific grant for this research from any funding agency in the public, commercial or not-for-profit sectors.

Competing interests None declared.

Patient consent for publication Not required.

Ethics approval This article is a document review of the NamFELTP programme efforts in field epidemiology and does not include human subjects. Programme documents required no ethical approval to access; however, administrative approval was obtained from the MoHSS. Confidentiality of past and current NamFELTP trainees was maintained.

Provenance and peer review Not commissioned; internally peer reviewed.

Data availability statement Data are available upon reasonable request.

Supplemental material This content has been supplied by the author(s). It has not been vetted by BMJ Publishing Group Limited (BMJ) and may not have been peer-reviewed. Any opinions or recommendations discussed are solely those of the author(s) and are not endorsed by BMJ. BMJ disclaims all liability and responsibility arising from any reliance placed on the content. Where the content includes any translated material, BMJ does not warrant the accuracy and reliability of the translations (including but not limited to local regulations, clinical guidelines, terminology, drug names and drug dosages), and is not responsible for any error and/or omissions arising from translation and adaptation or otherwise.

Open access This is an open access article distributed in accordance with the Creative Commons Attribution Non Commercial (CC BY-NC 4.0) license, which permits others to distribute, remix, adapt, build upon this work non-commercially, and license their derivative works on different terms, provided the original work is properly cited, appropriate credit is given, any changes made indicated, and the use is non-commercial. See: http://creativecommons.org/licenses/by-nc/4.0/.
ORCID iD

Kofi Mensah Nyarko http://orcid.org/0000-0002-1657-3167

\section{REFERENCES}

1 Countries by Population Density 2020 - StatisticsTimes.com. Available: http://statisticstimes.com/demographics/countries-bypopulation-density.php [Accessed 5 Dec 2020].

2 Jones DS, Dicker RC, Fontaine RE, et al. Building global epidemiology and response capacity with field epidemiology training programs. Emerg Infect Dis 2017;23.

3 Gregg MB. Field epidemiology. 3rd edn. New York: Oxford University Press, 2008. https://trove.nla.gov.au/version/9727137

4 Nguku P, Mosha F, Prentice E, et al. Field epidemiology and laboratory training programs have been in Africa for 10 years, what is their effect on laboratory-based surveillance? reflections from a panel at the African Society of laboratory medicine December 2014 Cape town meeting. Pan Afr Med J 2015;20:451

5 CDC. Field epidemiology training program (FETP). division of global health protection. global health, 2020. Available: https://www.cdc. gov/globalhealth/healthprotection/fetp/index.htm [Accessed 5 Dec 2020].

6 WHO. Global Health Observatory data repository. By category. Total NCD Mortality - Data by country. WHO. Available: https://apps.who. int/gho/data/node.main.A860 [Accessed 5 Dec 2020].

7 Guariguata L, de Beer I, Hough R, et al. Prevalence and knowledge assessment of HIV and non-communicable disease risk factors among formal sector employees in Namibia. PLoS One 2015;10:e0131737.

8 CDC. Namibia country profile, 2019. Available: https://www.cdc.gov/ globalhivtb/where-we-work/namibia/namibia.html [Accessed 5 Dec 2020].

9 Cdc. one health, 2020. Available: https://www.cdc.gov/onehealth/ index.html [Accessed 31 Oct 2020].

10 Reddy C, Kuonza L, Ngobeni H, et al. South Africa field epidemiology training program: developing and building applied epidemiology capacity, 2007-2016. BMC Public Health 2019;19:469.

11 Ropa B, Flint J, O'Reilly M, et al. Lessons from the first 6 years of an intervention-based field epidemiology training programme in Papua New Guinea, 2013-2018. BMJ Glob Health 2019;4:e001969.

12 WHO. Joint External Evaluation tool (JEE tool) - second edition. WHO. Available: http://www.who.int/ihr/publications/WHO_HSE_ GCR_2018_2/en/ [Accessed 5 Dec 2020].

13 ljaz K, Kasowski E, Arthur RR, et al. International Health Regulations-what gets measured gets done. Emerg Infect Dis 2012;18:1054-7.

14 Namibia: Regions, Cities \& Urban Localities - Population Statistics, Maps, Charts, Weather and Web Information. Available: http://www. citypopulation.de/Namibia.html [Accessed 11 Mar 2019].

15 Mupakeleni UN, Nyarko KM, Ananias F. Factors associated with schistosomiasis outbreak at Omindamba primary school, Omusati region, Namibia: a case-control study, March 2016. Pan Afr Med J;2017:28.

16 Cossaboom CM, Khaiseb S, Haufiku B, et al. Anthrax epizootic in wildlife, Bwabwata National Park, Namibia, 2017. Emerg Infect Dis 2019;25:947-50.

17 Nyarko KM, Mupakeleni UN, Ananias F, et al. An outbreak of schistosomiasis in a primary school in Omusati region, Namibia, March, 2016. Pan Afr Med J 2018;30:5.

18 André AM, Lopez A, Perkins S, et al. Frontline field epidemiology training programs as a strategy to improve disease surveillance and response. Emerg Infect Dis 2017;23.

19 Liberia workforce development (FETP) in action. Available: https:// www.cdc.gov/globalhealth/security/stories/liberia-workforcedevelopment.html [Accessed 5 Nov 2018].

20 McCourt W, Awases M. Addressing the human resources crisis: a case study of the Namibian health service. Hum Resour Health 2007;5:1.

21 School of Medicine. Univ. Namib, 2015. Available: http://www.unam. edu.na/school-of-medicine [Accessed 28 Jan 2019].

22 The global field epidemiology roadmap | TEPHINET. Available: https://www.tephinet.org/the-global-field-epidemiology-roadmap [Accessed 6 Jun 2019].

23 Makumbi M. Ministerial resolutions on Africa field epidemiology network (AFENET), Maputo, 2018. Available: http://www.afenet. net/index.php/news/news/463-ministerial-resolutions-on-africafield-epidemiology-network-afenet-maputo-2018 [Accessed 31 Oct 2020].

24 Namibian T. Anthrax kills 109 hippos in Bwabwata. The Namibian. Available: https://www.namibian.com.na/index.php?page=archiveread\&id=170288 [Accessed 19 Mar 2018]. 
25 Deadly anthrax outbreak in Zambia caused by Hippo meat. Available: https://www.healio.com/infectious-disease/zoonoticinfections/news/online/\%7Bda1b8ba2-641a-459a-ba1034f38368fea6\%7D/deadly-anthrax-outbreak-in-zambia-caused-byhippo-meat [Accessed 20 Jun 2018]

26 Sitali DC, Mumba C, Skjerve E, et al. Awareness and attitudes towards anthrax and meat consumption practices among affected communities in Zambia: a mixed methods approach. PLoS Negl Trop Dis 2017;11:e0005580.

27 Herriman R. Zimbabwe anthrax outbreak: 14 sickened, 1 death; linked to eating Hippo. outbreak news today, 2017. Available: http:// outbreaknewstoday.com/zimbabwe-anthrax-outbreak-14-sickened1-death-linked-eating-hippo-74560/ [Accessed 20 Jun 2018].

28 Ministry urges vaccination for rubella and measles - The Namibian. Available: https://www.namibian.com.na/152137/archive-read/ Ministry-urges-vaccination-for-rubella-and-measles [Accessed 17 Jun 2018].
29 Kaburi BB, Kubio C, Kenu E, et al. Evaluation of the enhanced meningitis surveillance system, Yendi municipality, Northern Ghana, 2010-2015. BMC Infect Dis 2017;17:306

30 Lopes $\mathrm{PH}$, Akweongo P, Wurapa F, et al. Bovine tuberculosis surveillance system evaluation, Greater-Accra region, Ghana, 20062011. Pan Afr Med J 2016;25:10.

31 Hikufe EH. Rabies sero-survey in vaccinated domestic dogs and knowledge assessment of rabies among dog owners, Ohangwena region, Namibia, 2016. Available: http://repository.unam.edu.na/ handle/11070/1696 [Accessed 19 Mar 2018].

32 López A, Cáceres VM. Central America field epidemiology training program (Ca FETP): a pathway to sustainable public health capacity development. Hum Resour Health 2008;6:27.

33 NamFELTP. Namibia field epidemiology and laboratory training program, Ministry of health and social services. 